text book which will be of interest to those who specialise in the management of pituitary adenomas as well as a wide range of specialists who may occasionally come into contact with these patients. I think both established consultants and trainees will enjoy this very reasonably priced contribution to the field.

\section{ROD LAING}

Handbook of Multiple Sclerosis. Second Edition; Revised and Expanded. Edited by STUART D COOK. (Pp 640; \$175.00.) Published by Marcel Dekker inc, New York. 1996. ISBN 0-8247-9726-4.

With a long list of eminent authors who have contributed a considerable amount to recent research on multiple sclerosis this book aims to provide a comprehensive update on the background of rapidly advancing research. It has a strong North American flavour with only two of the 42 authors based in other locations; this is reflected in the text and also in the interpretation of literature. One example of this is the rather egotistic idea that "Until the Canadian Collaborative Project on Genetic Susceptibility to Multiple Sclerosis is completed, the relative role of genetic and environmental factors in the causation of multiple sclerosis will remain obscure". The facts are that several groups including one in the United States are addressing this question and have since published their results which presumably were not available prior to publication of this book. The chapter by Hillbert provides a more balanced approach to genetic aspects of the disease, but one found oneself primed against further narrow interpretations early in the book.

Halfway through and I begin to warm to this tome, the classical arguments for and against the environmental contribution to disease aetiology are well researched and fluently written including the role of EAE and its contribution to the understanding of disease genesis. I soon found myself scoring the chapters and their authors and before long "the man of the match" emerged. John Prineas's review of the pathology was wonderfully eloquent and quite beautifully illustrated with some old favourites. My only beef would be that the black and white representations do not entirely do justice to the wonderful colour originals and their interpretation is slightly weakened because of this, although I am sure this was a financial decision. Another chapter worth mentioning in despatches is the review of neuroimaging in multiple sclerosis which has become so important in managing some of the clinical aspects of the disease, as a surrogate marker of disease activity and the value of new techniques and imaging sequences. I felt, however, that the edge of some of the information was dulled by the liberal use of "technospeak" which I would imagine we are all guilty of to some extent. Another minor complaint I would have is the variable citation format which seemed to switch from numbered to alphabetical intermittently and failed to provide a sense of comfort in the use of these references even by the end of the book.

Predictably one of the most controversial chapters was the presentation and interpretation of the interferon data in the treatment of multiple sclerosis. North America has wholeheartedly embraced the use of these drugs in the day to day management of multiple sclerosis. Europe and in particular the
United Kingdom has remained more circumspect. This book presents unequivocal support for the widespread use of interferon raising only questions about which type and how to manage side effects. It does not in my opinion provide an alternative view and does not address adequately the important questions of blinding and the relevance of a single point on the EDSS in those trials designed to determine an effect on the most important feature-namely, disability.

Overall this is a good read for the established features of the disease. I would, however, advise those interested in therapeutic advances to make their own interpretation of the data and to remember that this is a book which leans heavily on local practices and interpretations.

NEIL ROBERTSON

Neurological Disorders, Course and Treatment. Edited by THOMAS BRANDT, LOUIS $\mathbf{R}$ CAPLAN, JOHANNES DICHGANS, $H$ CHRISTOPH DIENER and CHRISTOPHER KENNARD. (Pp 1150; \$139.95.) Published by Academic Press, California. 1996. ISBN 012-125830-0.

Many large textbooks of neurology, by their very nature, contain vast amounts of information, sometimes presented in a turgid style, that the practising neurologist often finds difficult to access easily. This new textbook, as its title suggests, sets out to provide a practical guide to the clinical neurologist, with the emphasis on patient management. Any textbook that attracts a wide range of distinguished authors from both sides of the Atlantic is worth serious consideration, and the acid test of this volume is the frequency with which it has been consulted in the registrar's room over the last two months, and the ease with which the required facts have been extracted.

Each chapter is divided into various sections: clinical aspects, natural course, principles of therapy, practical management, and treatments no longer recommended. This is a refreshingly innovative approach, and on the whole works extremely well. It is a shame that some authors have strayed from this approach, as it makes referring to individual chapters a pleasure. The chapters are generally concise and well written, and one of the features I particularly liked about this book was its division into many small chapters each covering a specific and focused area. Symptoms which neurologists commonly encounter and which are often difficult to unravel, such as tinnitus and vertigo, are covered in their own right. The section on side effects of drugs commonly used in neurology is innovative and of great use.

I found this an excellent textbook-perhaps the most useful large textbook of neurology that I have come across in the past few years. Its success stems from its emphasis on the day-to-day practicalities of patient management rather than on factual material as in other reference books. It will undoubtedly find a place on the bookshelf of many neurology departments, and the editors and authors are to be congratulated on their efforts.

SANDIP SHAUNAK

Bickerstaff's Neurological Examination in Clinical Practice. Sixth Edition. By JOHN SPILlane. (Pp 383; $£ 39 \cdot 50$.) Published by Blackwell Science Ltd, Oxford. 1996. ISBN 0-86542-909-X.
This book was first published in 1962, and is now on it sixth edition. The fact that it has reached so many editions must be a comment on its success over the past 30 years. The problem is that the recipe for success in the era when this book was first published is not necessarily a guarantee of success in the 1990s. The learning process generally, not only in medicine, is much less didactic than it used to be. Although this book has been revised several times it still exudes a dry and uninspiring aura. Despite not being able to quibble with this book's factual content, the dense text and relative lack of illustrations (particularly in the context of neuroanatomy) made this heavy going.

The author comments in his preface that this was not intended to be a comprehensive textbook of neurology or of neurological diagnosis. However, by attempting to include aspects of both of these areas, the book fails to satisfy the reader in either. One immediately thinks of textbooks which much more successfully satisfy the needs of today's neurological trainee in providing a well written, well illustrated and accessible source of information with the emphasis on understanding the anatomical basis of the facts presented. Some of these have managed to evolve since first published and to integrate areas that have transformed clinical practice such as imaging in a way that this book doesn't quite achieve.

This may have been a useful book when first published, but I think that it is unlikely to appeal greatly to today's trainees or medical students. At $£ 39 \cdot 50$ it doesn't offer particularly good value to these groups.

SANDIP SHAUNAK

Operative Skull Base Surgery. Edited by MICHAEL TORRENS, OSSAMA AL-MEFTY and SHIGEAKI KOBAYASHI. (Pp $330 ; £ 125.00$.) Published by Churchill Livingstone, Edinburgh. 1996. ISBN 0-443-05079-1.

Subspecialisation rolls on apace. In the august establishment where I accomplished most of my postgraduate training, the Dental Institute had so many professors that, it was regularly suggested, there was one for each tooth. Although in neurosurgery we have not yet reached the point of one professor for each neurone, it is probable that the tidal wave of subspecialisation is now unstoppable. While in many areas of the discipline the old adage of knowing more and more about less and less applies, in the case of skull base surgery the growth of the subspecialty has had its advantages as it brings together the separate disciplines of neurosurgery, otolaryngology and maxillofacial surgery. The combined expertise of these different disciplines has made tackling the formidable technical problems of lesions around the skull base much less daunting than appeared to be the case only a few years ago. This book brings together the majority of the different operative approaches to the skull base currently in use. As might be expected in a multiauthored textbook, some of the chapters and, more crucially, some of the illustrations are clearer than others, but the editors are to be congratulated for managing to impose a relative uniformity of style. The illustrations are in monochrome and this seriously impairs their comprehensibility in some cases. However, in most chapters they are relatively easy to understand, although both the illustrative 